\title{
Is energy expenditure reduced in obese mice with mutations in the leptin/ leptin receptor genes?
}

\author{
Paul Trayhurn ${ }^{1,2 *}$ and Jonathan R. S. Arch ${ }^{1}$ \\ ${ }^{1}$ Clore Laboratory, University of Buckingham, Buckingham MK18 1EG, UK \\ ${ }^{2}$ Institute of Ageing and Chronic Disease, University of Liverpool, Liverpool L7 8TX, UK
}

(Received 20 May 2020 - Accepted 21 May 2020)

Journal of Nutritional Science (2020), vol. 9, e23, page 1 of 5

doi:10.1017/jns.2020.19

Abstract

Rodents with mutations in the leptin, or leptin receptor, genes have been extensively used to investigate the regulation of energy balance and the factors that underlie the development of obesity. The excess energy gain of these mutants has long been considered as being due in part to increased metabolic efficiency, consequent to reduced energy expenditure, but this view has recently been challenged. We argue, particularly though not exclusively, from data on $o b / o b$ mice, that three lines of evidence support the proposition that reduced expenditure is important in the aetiology of obesity in leptin pathway mutants (irrespective of the genetic background): (i) milk intake is similar in suckling $o b / o b$ and $+/$ ? mice; (ii) $o b / o b$ mice deposit excess energy when pair-fed to the ad libitum food intake of lean siblings; (iii) in several studies mutant mice have been shown to exhibit a lower RMR 'per animal' at temperatures below thermoneutrality. When metabolic rate is expressed 'per unit body weight' (inappropriately, because of body composition differences), then it is invariably lower in the obese than the lean. It is important to differentiate the causes from the consequences of obesity. Hyperphagic, mature obese animals weighing 2-3 times their lean siblings may well have higher expenditure 'per animal', reflecting the costs of being larger and of enhanced obligatory diet-induced thermogenesis resulting from the increased food intake. This cannot, however, be used to inform the aetiology of their obesity.

Key words: Energy expenditure: Gene mutations: Leptin: Leptin receptor: Metabolic efficiency: $o b / o b$ mice: Obesity: Thermogenesis

Animal models have been used extensively in studies on the regulation of energy balance and the factors that underlie the development of obesity. Perhaps the most widely used has been the genetically obese $o b / o b\left(L_{e p}^{o b} / L_{e p}^{o b}\right)$ mouse, the profound obesity of which results from a mutation in a single recessively inherited gene ${ }^{(1,2)}$. This gene encodes the hormone leptin, which is expressed and secreted principally by white adipocytes $^{(2)}$. Mutations in the leptin receptor gene are also associated with obesity, as evident in both the diabetic $d b / d b$ $\left(\operatorname{Lepr}^{d b} / \operatorname{Lepr}^{d b}\right)$ mouse and the fatty $f a / f a$ (Lepra $\left./ \operatorname{Lepr}^{f a}\right)$ rat. Each of these rodents with leptin pathway mutations are hyperphagic and this is an important factor in their obesity ${ }^{(1,3)}$. However, several types of study have indicated that the obese mutants are also more 'metabolically efficient' as a consequence of reduced energy expenditure ${ }^{(3)}$. The reduced expenditure has been attributed to decreased thermogenesis in brown adipose tissue ${ }^{(4-6)}$ - underpinning the extensive interest in this tissue - the implication of which is that leptin is a thermogenic hormone ${ }^{(7)}$.

The view that reduced expenditure is a feature of obese animals with a leptin pathway mutation and that the hormone is thermogenic (directly or indirectly) has, however, recently been strongly challenged ${ }^{(8)}$. It is argued that the reported hypometabolism in $o b / o b$ and $d b / d b$ mice, and in $f a / f a$ rats, comes 'from a misleading calculation artefact resulting from expression of energy expenditure per gram of body weight and not per intact organism $^{(8)}$. We consider this proposition here, focusing on the $a b / o b$ mouse as the key model, and conclude that reduced

* Corresponding author: Paul Trayhurn, email p.trayhurn@liverpool.ac.uk

(C) The Author(s), 2020. Published by Cambridge University Press on behalf of The Nutrition Society. This is an Open Access article, distributed under the terms of the Creative Commons Attribution-NonCommercial-NoDerivatives licence (http://creativecommons.org/licenses/by-nc-nd/4.0/), which permits non-commercial re-use, distribution, and reproduction in any medium, provided the original work is unaltered and is properly cited. The written permission of Cambridge University Press must be obtained for commercial re-use or in order to create a derivative work. 
energy expenditure is an important factor in the initiation and development of obesity in leptin pathway mutants.

\section{Energy expenditure and metabolic efficiency in ob/ob mice}

In considering the energetics of obese models, it is important to distinguish between the causes and the consequences of obesity; the critical question is whether reduced energy expenditure is a causal factor. The energetics of $o b / o b$ mice relative to their lean siblings will vary according to the circumstances, particularly the stage of development and degree of obesity, as well as whether they are hyperphagic at the time of measurement. Thus, for example, results from comparisons of adult lean and obese animals need to be interpreted carefully given the up to 3-fold difference in body weight and the elevated food intake of the obese.

There are three major lines of evidence that lead to the conclusion that leptin-deficient $o b / o b$ mice have a reduced energy expenditure and that this is an important component in the development of their obesity: (i) milk intake in suckling animals; (ii) pair-feeding studies in young, weaned animals; and (iii) measurements of RMR (Fig. 1).

It is important to note that $o b / o b$ mice have been studied principally with the mutant gene on two different backgrounds - C57Bl/6J and the mixed 'Aston' background - although the ob allele has also been transferred to other backgrounds ${ }^{(8)}$. Aston strain mice are larger and were developed, and have been widely employed, in the UK.

\section{Milk intake}

Increased body fat is evident in $o b / o b$ mice relative to their nonmutant $+/ ?(+/+, o b /+)$ siblings before weaning in animals with the mutant gene on either the $\mathrm{C} 57 \mathrm{Bl} / 6 \mathrm{~J}$ or Aston backgrounds ${ }^{(9,10)}$. For example, with the mutant gene on the Aston background body fat was reported to be $20 \%$ higher at $10 \mathrm{~d}$ and $72 \%$ higher at $17 \mathrm{~d}$ of age than in mice bearing the lean genotype ${ }^{(10)}$.

Measurements of milk intake during the suckling period have shown that it is similar whether the individuals in a litter bear the $o b / o b$ or $+/$ ? genotypes ${ }^{(11-13)}$. This is the case if intake is assessed either through test weighing following re-feeding after a fast ${ }^{(11)}$, or by more precise methods involving the administration of tritiated water to the dam ${ }^{(14)}$ or to the pups ${ }^{(13)}$. Administration of tritiated water to the dams indicated that intake was not elevated in the $o b / o b$ animals on the C57Bl/ $6 \mathrm{~J}$ background at either 10 or $17 \mathrm{~d}$ of age ${ }^{(14)}$. Similarly, administering tritiated water to the pups, the most accurate of these three approaches, showed that intake in Aston $o b / o b$ and $+/$ ? mice was the same between days 10 and 16 of life ${ }^{(13)}$.

In each of these studies, milk intake was measured 'per animal' - it was not expressed relative to body weight. Thus, the evidence indicates that the initiation and early development of obesity in $o b / o b$ mice occur without hyperphagia.

\section{Pair-feeding}

Several studies on the effect of food restriction on body weight and body fat of ob/ob mice post-weaning have been (a) Milk intake

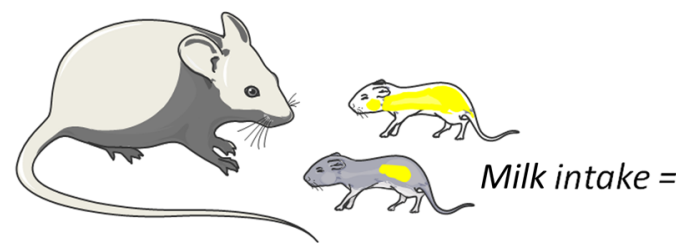

(b) Pair-feeding
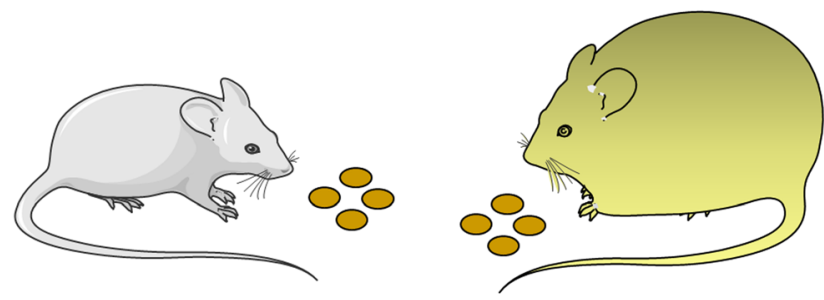

(c) Metabolic rate

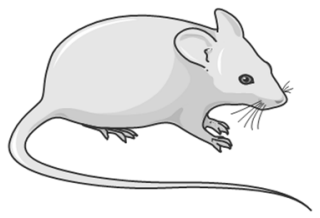

$\mathrm{O}_{2}>\mathrm{O}_{2}$

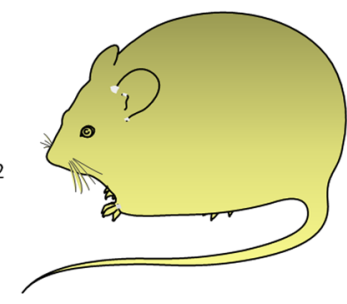

$+/ ?$

$a b / o b$

Fig. 1. Schematic representation of the main lines of evidence for increased metabolic efficiency, consequent to reduced energy expenditure, in $o b / o b$ mice. (a) Milk intake in suckling ob/ob and $+/$ ? mice; (b) pair-feeding studies in which $o b / o b$ mice were fed the ad libitum intake of lean siblings; (c) metabolic rate 'per animal' at temperatures below thermoneutrality. Mouse images are courtesy of Servier Medical Art (https://smart.servier.com).

undertaken ${ }^{(8)}$. However, the most appropriate approach to examining metabolic efficiency is full energy balance experiments in which mutant mice are pair-fed to the daily ad libitum food intake of their lean siblings, with energy deposition being the measured end point.

Such full energy balance has been performed on Aston $o b /$ $o b$ mice pair-fed to the ad libitum intake of lean $(+/$ ? $)$ siblings, employing the comparative slaughter technique (where the initial body composition of the experimental group is estimated by reference to a matched group of animals sampled at the start of the experiment $)^{(15)}$. In this study, the $o b / o b$ mice received their food in two daily meals in order to minimise any meal-feeding effects, the larger being presented just before the onset of the dark period. Both the rate of fat gain, and importantly the total energy gain, were higher in the obese mice than in the siblings to which they were yoked ${ }^{(15)}$. The study was conducted at several temperatures between thermoneutrality $\left(32-33^{\circ} \mathrm{C}\right)$ and $17^{\circ} \mathrm{C}$, and at each the energy deposition of the $o b / o b$ was greater than that of the lean; at room temperature $\left(23^{\circ} \mathrm{C}\right)$, the energy deposited was $2 \cdot 3$-fold higher in the obese than the lean ${ }^{(15)}$. Weight gain was lower in the 
obese, irrespective of environmental temperature, emphasising the importance of examining energy balance.

These energy balance studies clearly indicate that $o b / o b$ mice exhibit a higher metabolic efficiency and can develop obesity in the absence of hyperphagia, reflecting a reduction in one or more components of energy expenditure. Interpretation of these observations is potentially confounded in that food restriction can induce torpor in mice ${ }^{(16,17)}$. However, torpor is not necessarily a factor in the enhanced metabolic efficiency of (Aston) $o b / o b$ pair-fed to the habitual intake of lean siblings; most experiments demonstrating torpor have involved either fasting $^{(16,18)}$, or feeding the mutant mice considerably less than the normal intake of the lean ${ }^{(17,19,20)}$. Torpor is more likely to be evident with severe food restriction than with the limited restriction in the yoked pair-feeding studies.

Nevertheless, if torpor is a factor in the increased energy deposition of $o b / o b$ mice relative to lean siblings when food is restricted in pair-feeding, then this does not of itself negate the concept of the mutants having an elevated metabolic efficiency. Rather, it provides a mechanistic basis with the decreased body temperature resulting in energy saving through reduced thermogenesis (and other components of expenditure).

A different form of pair-feeding was observed in a study in which mice were able to overfeed through the provision of a cafeteria diet ${ }^{(21)}$. Serendipitously, the energy consumption of the cafeteria-fed lean animals was similar to that of the $o b / o b$ on their normal diet, so no food restriction was imposed on the obese. The energy gain and gross efficiency were both nearly 3 -fold greater in the obese, consistent with impaired facultative diet-induced thermogenesis in the mutants ${ }^{(21)}$. Indeed, the apparent energy expenditure of the obese was $<75 \%$ of that of the cafeteria-fed animals.

\section{Metabolic rate}

A number of studies have measured $\mathrm{RMR}$, or $\mathrm{O}_{2}$ consumption, in $o b / o b$ mice compared with lean siblings. There are several important variables that need to be considered in interpreting the results, foremost of which is the index of body weight used to express expenditure. Energy expenditure is invariably lower in the obese when expressed 'per $g$ body weight', as is commonly done, or on the basis of metabolic body size (body weight $\left.{ }^{0 \cdot 67 / 0 \cdot 75}\right)^{(22-26)}$. This is, however, unsurprising given that the obese animals may weigh up to three times more than their lean siblings, with the additional weight being due to white adipose tissue with its considerable quantity of TAG.

Expressing metabolic rate 'per unit body weight', or an index of metabolic size, is appropriate in comparing animals of widely different size - such as between species - but in energetic studies lean and obese siblings should be compared on a 'per animal' basis ${ }^{(8,27)}$. If expenditure is expressed 'per animal' then in some studies it is reported to be lower in the obese than the lean, whether on Aston or C57Bl/6J backgrounds ${ }^{(15,22,28,29)}$, while in others it appears not to be reduced $^{(8)}$. There are several points to consider in interpreting these different results. First, if body weight is 2- to 3-fold greater, then RMR might be expected to be higher in order to meet the energetic costs implicit in the elevated body mass. Second, the hyperphagia of the obese animals leads to an increased energy cost associated with the processing of additional food - obligatory diet-induced thermogenesis. Thus, the failure to observe reduced energy expenditure in some studies may simply reflect the consequences of comparing very obese, hyperphagic mice with normal-weight lean siblings consuming less food.

Indeed, it can be argued that mature, hyperphagic obese mice should exhibit higher energy expenditure than their lean siblings and that it is anomalous that this is not always the case. The key reference is young lean and obese animals that do not exhibit large differences in body weight and food intake. This is evident in 18 -d-old $\mathrm{fa} / \mathrm{fa}$ rats where $\mathrm{O}_{2}$ consumption 'per animal' is lower since body weight is essentially the same as for lean siblings ${ }^{(30)}$.

There are other variables between metabolic rate studies which may modify conclusions. These include environmental temperature and whether the animals were restrained or anaesthetised. With respect to environmental temperature, BMR, as measured by resting energy expenditure at thermoneutrality, is generally found to be similar, or even slightly elevated, in $o b / o b$ mice 'per animal' ${ }^{(8)}$. However, this does not indicate that they are not 'hypometabolic', or that the obesity is 'entirely a result of their excessive food intake', in contrast to what has been suggested ${ }^{(8)}$, but simply that there is no reduction in BMR.

RMR at the temperatures at which mice are usually maintained and studied - some $10^{\circ} \mathrm{C}$ below thermoneutral - will include the considerable energy costs of homoeothermy. For mice at $20-22^{\circ} \mathrm{C}$, this is up to half their total resting energy expenditure $^{(31)}$. And while the metabolic rate of $o b / o b$ mice at thermoneutrality is not lower than that of the lean, generally the increase, whether expressed 'per unit weight' or 'per animal', as environmental temperature is lowered is less in the obese than the lean ${ }^{(24,31)}$.

\section{Genetic background and mutant genes}

The majority of studies on $o b / o b$ mice have used animals with the mutant gene on the C57BL/6J background, while 'Aston' strain mice have been primarily used in the UK. Apparent differences between the two backgrounds have been emphasised, particularly in relation to whether energy expenditure is indeed lower 'per animal' in the mutants ${ }^{(8)}$. While it appears clear that reduced expenditure 'per animal' occurs in the Aston $o b / o b$ strain, it is argued that this is not the case in those with the mutant gene on the $\mathrm{C} 57 \mathrm{Bl} / 6 \mathrm{~J}$ background $^{(8)}$ and that Aston mice represent an exception. However, as noted above, lower expenditure has been observed in C57Bl/6J ob/ob mice ${ }^{(28,29)}$. Furthermore, similar milk intake is evident in suckling $o b / o b$ mice of this background, with energy deposition being increased over the same period ${ }^{(14)}$.

It should be noted that reductions in energy expenditure (per animal) relative to lean animals are also exhibited by $d b / d b$ mice on the C57BL/Ks background ${ }^{(32)}$. Energy balance studies in which young $\mathrm{C} 57 \mathrm{BL} / \mathrm{Ks}$, or $\mathrm{C} 57 \mathrm{Bl} / 6 \mathrm{~J}, d b / d b$ mice were pair-fed to the ad libitum food intake of their lean siblings also observed increased fat deposition and metabolic efficiency 
in the mice with the leptin receptor mutation, similar to $a b / o b$ mutants ${ }^{(33,34)}$. We would argue, therefore, that Aston $o b / o b$ mice are not anomalous, but broadly reflective of the characteristics of a leptin pathway mutation.

A further important model is the $f a / f a$ rat which, like the $d b /$ $d b$ mouse, has a mutation in the leptin receptor gene. The general arguments relating to the mouse mutants also apply to the $f a / f a$ rat. It is apparent that in suckling $f a / f a$ rats, energy expenditure is reduced relative to the $+/$ ? siblings - although the data are expressed 'per g body weight', at this point body weight is similar in the different genotypes ${ }^{(30)}$. Pair-feeding studies also indicate that the metabolic efficiency of $f a / f a$ rats is greater than their lean siblings ${ }^{(35,36)}$, and torpor is not known to occur in rats.

\section{General comments}

The analysis in this article supports the long-standing view that a reduction in energy expenditure is a component in the development of obesity in both $o b / o b$ mice and leptin receptor mutants. The data in Aston strain $o b / o b$ animals clearly demonstrate that: (i) the early development of obesity in suckling animals takes place without any increase in milk intake; (ii) young obese mutants pair-fed to the ad libitum intake of lean siblings exhibit an increased metabolic efficiency, consequent to reduced energy expenditure; and (iii) measurements of RMR indicate that it is lower 'per animal' in the obese than the lean at temperatures below thermoneutrality (Fig. 1). In the more widely employed mice with the leptin mutation on the C57Bl/6J background, milk intake data and our own studies on $\mathrm{RMR}^{(28,29)}$ paint a similar picture; we are not aware of full energy balance studies on $\mathrm{C} 57 \mathrm{Bl} / 6 \mathrm{~J} o b / o b$ mice.

It is emphasised that in agreement with other authors ${ }^{(8,27)}$, it is important to present metabolic rate data 'per animal'. It is also important to recognise that erroneous conclusions on the energetics of the obese may be made when based on hyperphagic animals weighing 2-3 times more than lean siblings consuming a normal amount of food. The central issue is causality - whether energy expenditure is reduced in younger $o b / o b$ mice, underpinning the development of their obesity. As the animals become larger with substantial obesity, and are hyperphagic, energy expenditure would be expected to rise and may not necessarily be below that of the lean.

Leptin is well-recognised to regulate appetite, administration of the hormone leading to a reduction in food intake in leptindeficient mutants ${ }^{(37)}$. The generally accepted proposition is that leptin-deficient mice also exhibit a decrease in thermogenesis mediated by brown adipose tissue ${ }^{(4-6)}$. It is now proposed that leptin is not a thermogenic hormone, but rather that it affects the regulation of body temperature through shifting thermoregulatory threshold and opposing torpor ${ }^{(8)}$. However, this would still indicate that leptin is thermogenic, albeit indirectly so. Alternative views include the recent proposal that leptin stimulates a hypothalamus-adrenal medulla-brown adipose tissue axis, thereby inducing lipolysis and increasing body temperature ${ }^{(38)}$.

In conclusion, we consider that the balance of evidence firmly supports the view that energy expenditure is reduced in $o b / o b$ mice, and in leptin receptor obese mutants, and certainly so during the critical period of the early development of their obesity. This reduced expenditure has, of course, underpinned the interest in brown adipose tissue since the late $1970 \mathrm{~s}^{(3-6)}$.

\section{Acknowledgements}

The authors are in receipt of no specific grant from any funding agency, commercial or not-for-profit sectors, relevant to the present article.

Both authors conceived this review article, with P. T. drafting the manuscript, and with J. R. S. A. providing subsequent suggestions and comments.

The authors have no conflicts of interest.

\section{References}

1. Bray GA \& York DA (1979) Hypothalamic and genetic obesity in experimental animals: an autonomic and endocrine hypothesis. Physiol Rev 59, 719-809.

2. Zhang Y, Proenca R, Maffei M, et al. (1994) Positional cloning of the mouse obese gene and its human homologue. Nature 372, 425-432.

3. Trayhurn P (1984) The development of obesity in animals: the role of genetic susceptibility. Clinics Endocrinol Metab 13, 451-474.

4. Himms-Hagen J (1989) Brown adipose tissue thermogenesis and obesity. Prog Lipid Res 28, 67-115.

5. Trayhurn P (1986) Brown adipose tissue and energy balance. In Brown Adipose Tissue, pp. 299-388 [P Trayhurn and DG Nicholl, editors]. London: Edward Arnold.

6. Trayhurn P (2017) Origins and early development of the concept that brown adipose tissue thermogenesis is linked to energy balance and obesity. Biochimie 134, 62-70.

7. Friedman JM (1997) Leptin, leptin receptors and the control of body weight. Eur J Med Res 2, 7-13.

8. Fischer AW, Cannon B \& Nedergaard J (2020) Leptin: is it thermogenic? Endocrine Rev 41, 232-260.

9. Boissonneault GA, Hornshuh MJ, Simons JW, et al. (1978) Oxygen consumption and body fat content of young lean and obese $(o b / o b)$ mice. Proc Soc Exp Biol Med 157, 402-406.

10. Thurlby PL \& Trayhurn P (1978) The development of obesity in pre-weanling ob/ob mice. BrJ Nutr 39, 397-402.

11. Lin PY, Romsos DR \& Leveille GA (1977) Food intake; body weight gain; and body composition of the young obese $(o b / o b)$ mouse. J Nutr 107, 1715-1723.

12. Rath EA, Salman DMW \& Hems DA (1979) Effect of acute change in ambient temperature on fatty acid synthesis in the mouse. FEBS Lett 108, 33-36.

13. Contaldo F, Gerber H, Coward WA, et al. (1981) Milk intake in preweanling genetically obese $(o b / o b)$ mice. In Obesity: Pathogenesis and Treatment, pp. 319-322 [G Enzi et al. editors]. London and New York: Academic Press.

14. Rath EA \& Thenen SW (1979) Use of tritiated water for measurement of 24-hour milk intake in suckling lean and genetically obese (ob/ob) mice. J Nutr 109, 840-847.

15. Thurlby PL \& Trayhurn P (1979) The role of thermoregulatory thermogenesis in the development of obesity in genetically obese (ob/ob) mice pair-fed with lean siblings. Br J Nutr 42, 377-385.

16. Webb GP, Jagot SA \& Jakobson ME (1982) Fasting-induced torpor in Mus musculus and its implications in the use of murine models for human obesity studies. Comp Biochem Physiol 72A, 211-219.

17. Himms-Hagen J (1985) Food restriction increases torpor and improves brown adipose thermogenesis in $o b / o b$ mice. $A m J$ Physiol Endocrinol Metab 248, E531-E539.

18. Gavrilova O, Leon LR, Marcus-Samuels B, et al. (1999) Torpor in mice is induced by both leptin-dependent and -independent mechanisms. Proc Natl Acad Sci U S A 96, 14623-14628. 
19. Bolze F, Morath V, Bast A, et al. (2016) Long-acting PASylated leptin ameliorates obesity by promoting satiety and preventing hypometabolism in leptin-deficient Lep ${ }^{o b / o b}$ mice. Endocrinology 157, 233-244.

20. Skowronski AA, Ravussin Y, Leibel RL, et al. (2017) Energy homeostasis in leptin deficient $\operatorname{Lep}^{o b / o b}$ mice. PLOS ONE 12, e0189784.

21. Trayhurn P, Jones PM, McGuckin MM, et al. (1982) Effects of overfeeding on energy balance and brown fat thermogenesis in obese $(o b / o b)$ mice. Nature 295, 323-325.

22. Mayer J, Russell RE, Bates MW, et al. (1952) Basal oxygen consumption of hereditarily obese and diabetic mice. Endocrinology $\mathbf{5 0}$, 318-323.

23. Kaplan ML \& Leveille GA (1974) Core temperature, oxygen consumption, and early detection of $o b / o b$ genotype in mice. Am J Physiol 227, 912-915.

24. Hull D \& Vinter J (1984) The development of cold-induced thermogenesis and the structure of brown adipocyte mitochondria in genetically-obese $(o b / o b)$ mice. Br J Nutr 52, 33-39.

25. Pelleymounter MA, Cullen MJ, Baker MB, et al. (1995) Effects of the obese gene product on body weight regulation in $o b / o b$ mice. Science 269, 540-543.

26. Martins FF, Bargut TCL, Aguila MB, et al. (2017) Thermogenesis, fatty acid synthesis with oxidation, and inflammation in the brown adipose tissue of $o b / o b(-/-)$ mice. Annal Anat 210, 44-51.

27. Butler AA \& Kozak LP (2010) A recurring problem with the analysis of energy expenditure in genetic models expressing lean and obese phenotypes. Diabetes 59, 323-329.

28. Arch J, Ainsworth AT, Ellis R, et al. (1984) Treatment of obesity with thermogenic $\beta$-adrenoreceptor agonists: studies on BRL 26830A in rodents. Int J Obesity 8, Suppl. 1, 1-11.
29. Wilson S, Arch J \& Thurlby PL (1984) Genetically obese C57BL/6 $o b / o b$ mice respond normally to sympathomimetic compounds. Life Sci 35, 1301-1309.

30. Kaplan ML (1979) Consumption of $\mathrm{O}_{2}$ and early detection of $f a / f a$ genotype in rats. Metabolism 28, 1147-1151.

31. Trayhurn P \& James WP (1978) Thermoregulation and nonshivering thermogenesis in the genetically obese $(o b / o b)$ mouse. Pflügers Arch Eur J Physiol 373, 189-193.

32. Trayhurn $\mathrm{P}(1979)$ Thermoregulation in the diabetic-obese $(d b / d b)$ mouse. The role of non-shivering thermogenesis in energy balance. Pflïgers Arch Eur J Physiol 380, 227-232.

33. Cox JE \& Powley TL (1977) Development of obesity in diabetic mice pair-fed with lean siblings. J Comp Physiol Psych 91, 347-358.

34. Trayhurn P \& Fuller L (1980) The development of obesity in genetically diabetic-obese $(d b / d b)$ mice pair-fed with lean siblings. The importance of thermoregulatory thermogenesis. Diabetologia 19 , 148-153.

35. Bray GA, York DA \& Swerloff RS (1973) Genetic obesity in rats. I. The effects of food restriction on body composition and hypothalamic function. Metabolism 22, 435-442.

36. Pullar JD \& Webster AJF (1974) Heat loss and energy retention during growth in congenitally obese and lean rats. Br J Nutr 31, 377-392.

37. Harris RB (2000) Leptin - much more than a satiety signal. Annu Rev Nutr 20, 45-75.

38. Perry RJ, Lyu K, Rabin-Court A, et al. (2020) Leptin mediates postprandial increases in body temperature through hypothalamus-adrenal medulla-adipose tissue crosstalk. J Clin Invest 130, 2001-2016. 